\title{
Building Blocks of the i-Society Value Chain Assessment Model
}

\author{
Elham Ziaeipour \\ ITRC \\ Ziaepour@yahoo.com
}

\author{
Alireza Taghizadeh \\ IEEE student member \\ alireza.taghizadeh@ieee.org
}

\author{
Ayoub Mohammadian \\ University of Tehran \\ mohamadian@ut.ac.ir
}

\author{
Farid Khoshalhan \\ K.N Toosi University \\ khoshalhan@kntu.ac.ir
}

\begin{abstract}
Nowadays, it is increasingly acknowledged that the information delivered through the use of ICT has become a core aspect of international socioeconomic development. So our society is forming anew as an Information society. The proposed isociety value chain assessment model in this paper includes all supportive and primary building blocks for creating value in society. Furthermore several different dimensions have been defined for each building block. In the end, by defining some indicators for each dimension, it has been derived appropriate conclusions have been derived to take effective decisions related to fostering the development processes of i-society in Iran as a case study.
\end{abstract}

Keywords: value chain, assessment model, building block, information society, e-services

\section{Introduction}

Information and Communication Technologies (ICTs) is probably the most frequently used term of our times, developed to include a variety of communications technologies and devices, as well as the entirety of services and applications associated with them.

The role of ICT in this global development lies less in the technology itself, than in its ability to create greater impacts on the society. Consequently, values added from ICT become more important than its infrastructures. The aim of this paper is proposing a value chain model for i-society and determining its building blocks. The developed model also can be used to monitor and evaluate progress in achieving the goals of i-society. Without some indication of how all building blocks of society are adapting to the installation and application of ICTs, there can be no way of understanding whether the shift towards an information society is actually taking place, or indeed, working in positive ways. Furthermore, there can be no understanding of future policy steps without reference to the current status of ICT implementation and its applications [1].

Even though there has been a proliferation of isociety measures in recent years, but analyses of the indicators of the "information society" are still far from responsive to the needs of many stakeholders and continue to suffer from a number of serious limitations [2]

E-Readiness assessment models are one of the most important analytical tools to determine internal strength and weakness, environmental opportunities and threats. It helps us to recognize new markets, innovative opportunities and services, governmental potentials to make money and possible bottlenecks in the road of developing countries. So it is considered as a planning tool for developing ICT in societies.

In recent years, a group of new assessment models have been introduced that were tuned according to the national and organizational levels separately. Each one has its own definition of eReadiness and covers some specific areas [3]. Some countries with considering their views of ICT development and its aspects, proposed new models to assess some specific building blocks which results a kind of customized models for those countries. Choosing the right model for assessment has become a new challenge for decision makers in developing countries.

There are two main generations of assessment models, the first generations was used as benchmarking tools, but new generations are prepared like a planning tool assisting decision makers to develop new goals for i-society [4].

As a matter of fact the first generation of assessment models, utilizes static factors for comparing countries, and as a result they are unable to find answer for specific requirements and features of those countries [4].

Most first generation models have been developed in limited areas such as e-Business while new frameworks try to provide flexible tools for different levels of i-society and considering all aspects such as economy, culture and politic [4].

In this paper, Instead of providing a mere descriptive literature review, our aim is to propose a value chain for defining building blocks of the isociety. After prioritizing and weighting each of the building blocks, we assess current position of the esociety in Iran and present assessment results on the implementation progress in order to have suggestion for improvement of i-society in Iran.

The rest of the paper is organized as follows: first of all, concept of i-society has been clarified. Second, some important assessment models have been explained. Then value chain model for developing i-society have been proposed. After that, 
the building blocks of the model have been weighted and prioritized based AHP method .finally current status of i-society in Iran has been assessed by this model.

\section{Literature review}

In this section, the concept of the information society has been explained in more detail and then a classification from existing i-society assessment models has been discussed.

\section{1. i-society concept}

Nowadays, it is increasingly acknowledged that the information delivered through the use of ICT has become a core aspect of international socioeconomic development. So the first challenge is to determine what it is that one is measuring. Is it information in society or an information society? Is it information or knowledge, or both, or ICT? Is it present state, or readiness, or potential, or outcomes, or impacts? Beyond the intentions and definitions, there is often not much difference in the various measurements and even less in their interpretation and utilization especially in policymaking [2]

Information technologies are increasingly permeating our areas of living and working. Our society is forming anew as an "information society". i-Society is a broad term used to describe a research area covering aspects of digital technologies for large user communities. In this paper, Our primary research materials consist of recent academic and managerial articles and books on the subject labelled under such headings as "e-society”, "digital society", "information society", "knowledge society", "network society" and "society e-readiness".

The emergence of the new technologies has prompted an intense discussion about the changing organizing principles of economic activities [5]. In addition, New opportunities for communication and information processing are questioning the validity of established social structures in politics, industry, science and culture and the i-society concept is seen to emerge [6]. So, in this paper, we argue that all aspects of the society will be changed. However, there seems to no consensus on the building blocks of the e-society. For instance, Castells [5] focuses on the affecting aspects of the new technologies and considers its informational character, networking logic, flexibility, functioning as an integrated system. Some other researchers focus on the changing managerial activities and decision-makings based on knowledge. Furthermore, recent years have seen the emergence of various electronic services in an attempt to facilitate everyday life and improve the way that common tasks are being carried out in organizations [7]
So in order to participate in shaping the emerging new societal reality, as shown in Figure1, there is a need for a constructive understanding between different layers of the society that includes individual, organizational, industrial, national, regional and international layers. By considering these layers, we can identify desirable technologies and goals and mobilize the existing potentials for their realization. In order to move into an information society, all the mentioned layers must be introduced into policy equations.

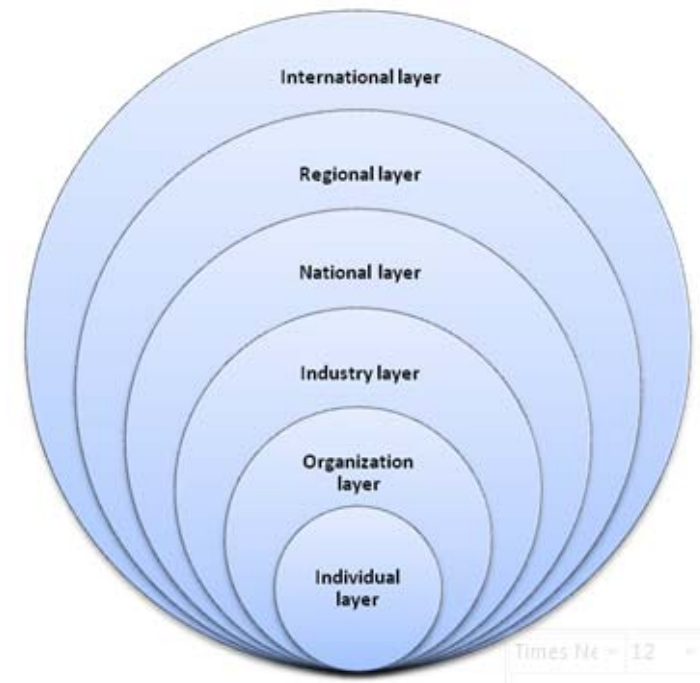

Figure 1. Different layers of i-society

In result, Information society is going to introduce a new model of society, which includes following features:

- Traditional meanings of education, business, economy and trade will be changed.

- Material values will be substituted by informational values.

- Information will be created and distributed immediately.

- Information processing will be replaced with industrial or agricultural activities

- Any kind of processing activitty will be done electrically.

- Time and place will not be important barriers anymore..

- Information and communication technology will create new skills and job opportunities.

- The human relationships will be redefined.

- New political, economical and social indicators will be introduced as well as management and organizational processes

\subsection{I-society assessment models}

Evaluating information society progress enables government to project proper targets to migrate toward information society. It is necessary to evaluate the maturity level of information society in 
order to allocate resources. The results of such an evaluation not only determine current position of a country in developing information society but also determine ranking of a country in international or regional levels. Information society assessment tools also can be applied as a powerful tool at the hand of policy makers to properly plan and direct investments.

Different assessment tools have been proposed until now. E-readiness models are the most important assessment tools. E-readiness has been defined in different ways. It might refer to a country's ability to take advantages of the internet as an engine of economic growth and human development [9, 8]. CSPP considered e-readiness as a community that has high penetrate in a competitive market; with high access to ICT applications in schools, government offices, businesses, healthcares and homes; regards to user privacy and online security [11]. The centre of International Development at Harvard defines ereadiness in relation to a society that has: the necessary physical infrastructure (high bandwidth, reliability and affordable prices); integrated ICTs through out business, communities and government and universal access [11]. Likewise, the McConnell International defines e-readiness in relation to a country that has extensive usage of computers in schools, businesses, government, homes; affordable reliable access in a competitive market: free trade; skilled workforces and training in schools; a culture of creativity; government-business partnerships; transparency and stability in government and legal system ; secure networks and personal privacy; regulations allowing digital signatures and encryption; consumers' trust in e-commerce security and privacy; more trained workers; lower training costs and lower costs for e-commerce technology[4].

Some of i-society assessment models which have been investigated in this paper are as follow:

- Models which have been provided by international unions and organizations such as UNDP, UNCTAD and World Bank [19].

- Models which have been suggested by academies, forums and institutes all over the word such as, NRI by Harvard university[10] McConnell International [12], CSPP[18],APEC[16], WITSA [17], EUI [21] , MIT[4], STOPE [13] and Fuzzy based model Davidrajuh [12]

- Organizational level models such as Rashid \& Qarim, Molla \& Licker , Ozer, Thache , Zhuk, Akkeren.[20]

- National proposed models and frameworks such as, ICT development model by Hanafizadeh [19], SME based e-Readiness model by Hoorali[14], e-Policy model based on ICT factors evaluations by Mohamadian [15]
- Localized models and best practices in different countries such as India, south Korea, Thailand, Pakistan, Russia, Bulgarian, Sirylanka[19]

\section{Proposed model for information society value chain}

Information society projects in most countries often have concentrated on consumption, and neglect the production side. This is confirmed by recent research, especially in software and other segments which are considered natural playing fields for developing countries [24]. It is obvious that recent isociety models are not comprehensive and are not useful for correct decision-making in the societies [15], because for intelligence decisions making, we also need to evaluate the ICT outcomes and impacts on the society as values which are created based on those ICT infrastructures and applications.

Policy makers strongly need to evaluate all the ICT effects on the different segments of the society. Such as considering advantages for households, businesses, governments and overall impacts on the economic, politic, culture and society, because ultimate goal of the every country is to use ICT to stimulate better quality in the life. In this way, policy makers should identify priorities in i-society in order to allocate resources correctly. So the most important building block of i-society should be impact of digital technologies, particularly the internet on society. For instance, Turkey country expects to improve its global competitiveness in all areas by implementing i-society with a significant social and economic impact [24].

Considering the ultimate goal of the information society, which is using ICT as a development accelerator for different sectors of society, an established e-infrastructure in the society beside a chain of related activities is necessary. To reach to a sustainable information society, the focus of the governments should be on adding values and gaining competitive advantages for different sectors of the society by ICT.

Value chain model is one of the best models for describing and analyzing value and competitive advantage in business level. Value chain is a concept from business management that was first described and popularized by Michael Porter. It is a model that helps to analyze specific activities through which firms can create value and gain competitive advantage [25]. A value chain is a chain of activities for a firm operating in a specific industry, but we apply the concept of this model for a society.

In this model, all activities can be divided in two main groups, Primary and Supportive. The Primary activities are sequential and interdependent. These related activities can create values by producing 
synergy, but supportive activities are parallel with all primary activities in order to strengthen them.

As depictured in Figure2, to present value chain of information society and to identify its building blocks, concepts of Porter's value chain have been used. This means that ICT development in each society should be based on competitive advantage and the local values of that society. By utilizing the proposed model, we can identify position of each building block and their inter-relations. The rest of this section, provide more details of proposed model and its applications.

Base on this model, the first things to identify are discovering specific values and competitiveness of ICT in target society. As said in prior section of this paper, expected values of the society can be affected from different layers of the society such as individual, organizational, industrial, national, regional and international layers. So the first question is what ICT impacts in macro level are and then we should consider possible ICT outcomes in micro level. Results of these assessments can assist policy makers to mobilize investments and assign resources in sectors with more outcomes and higher impacts.

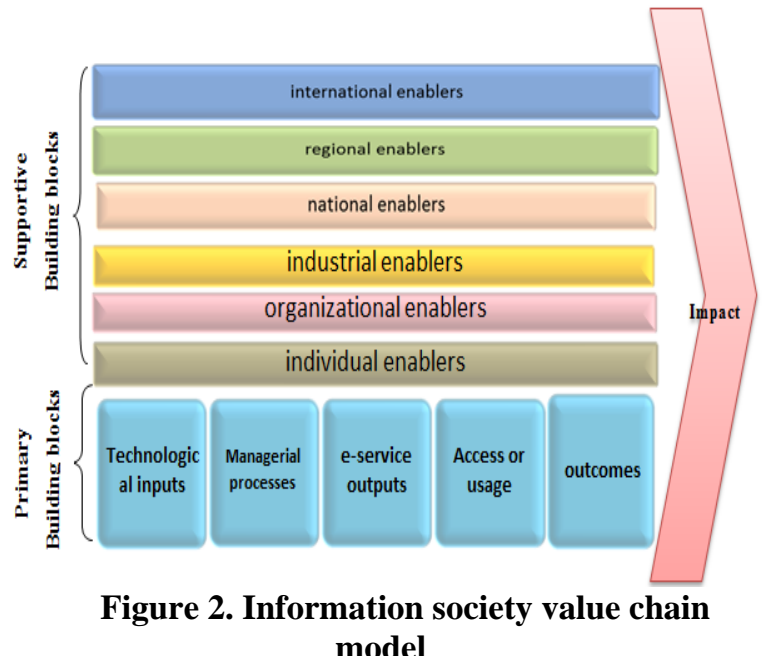

As mentioned before, it is necessary to have an alignment among the building blocks of value chain. Then, the next building block in this chain is the amount of access for the households, businesses and governments. Each of three sectors that create more values should have more access to ICT services. The next step is defining required kind of ICT services based on determined diffusion. After that, we can know what kinds of management processes are required and finally, what technological resources should be provided.

Additionally, as illustrated in the Figure, there is another group of activities or building blocks that act as enablers. This group of activities support the primary blocks. For example on the one hand, in external environment, regional and international supporters (e.g. creating regional cooperative organizations or utilizing experiences of the international organizations), can accelerate to develop information society inside a country. On the other hand, in internal environment, existing potentials and capabilities in national system and its subsystems such industries, organizations and individuals can improve the information society development.

Some of special features of the proposed value chain model for information society development are as follows:

1- Creating a comprehensive perspective including both big picture and its details.

2- Help managers to have a better understanding about different ICT aspects and values

3- Identifying the strengths, weaknesses, opportunities and threats of ICT for the society.

4- Applied as a tool for ICT strategic planning and policy making in national level.

5- Evaluating and tracking all layers of the society

6- Considering all affecting and affected building blocks.

7- Policy makers and industry can use this model to respond better to the needs and demands of the new i-society citizen

It should be mentioned that, according to the proposed model in this paper, each country should have a customized model based on own values and competitive advantages. So, there is no single universal model for all the countries. As an example, the concentration of country A can be on social activities, so they try to develop e-education services. But in country $\mathrm{B}$, the focus might be on economic activities and developing e-commerce. In result, the priorities for developing information society in each county should be based on identified specific values of that country and we should not compare countries with each other.

\section{Building blocks of the i-Society value chain model}

Based on value chain approach the following questions should be reposed to determine building blocks of i-society [23]:

1. Which building blocks and dimensions from external environment are enablers in i-society development?

2. Which building blocks and dimensions from internal environment are enablers in i-society development?

3. What are technological prerequisites of isociety?

4. How is i-society managed in a country?

5. What are the deliverables of i-society?

6. Who will access and use i-society deliverables?

7. How much are the outcomes of i-society development? 
8. How much are the impacts of i-society development?

With attention to the important role of value creation in proposed dimensions, reaching to a common sense of value in national level is vital. There are lots of different definitions for values in organizational level, with taking this assumption that value in national level, create after e-Service deployment in that country, we will reach to this conclusion that value in each country is different [23]. In the table1, the proposed building blocks and dimensions of i-society have been shown. Here we consider environmental building blocks (regional and international) and internal building blocks (national, industrial, business and individuals) as barriers or enablers and. It's obvious that with proper management, technological building blocks can bring better e-Services. On the one hand, adoption and deployment of e-services by individuals, businesses and governments have outcomes and on the other hand, on the society as a whole have impacts which appear as value for each society.

Table 1. Proposed layers, building blocks and Dimensions of i-society value chain model

\begin{tabular}{|c|c|c|}
\hline layers & $\begin{array}{l}\text { building } \\
\text { blocks }\end{array}$ & dimensions \\
\hline \multirow{2}{*}{$\begin{array}{c}\text { Supportive } \\
\text { External } \\
\text { Environment }\end{array}$} & International & $\begin{array}{c}\text { Technology, } \\
\text { Society, } \\
\text { Economy, Policy }\end{array}$ \\
\hline & Regional & $\begin{array}{c}\text { Technology, } \\
\text { Society, } \\
\text { Economy, Policy }\end{array}$ \\
\hline \multirow{4}{*}{$\begin{array}{c}\text { Supportive } \\
\text { Internal } \\
\text { environment }\end{array}$} & National & $\begin{array}{c}\text { Society, } \\
\text { Economy, } \\
\text { Policy, Research } \\
\text { \& Development }\end{array}$ \\
\hline & Industries & $\begin{array}{c}\text { Competitors, } \\
\text { Customers } \\
\text { Suppliers, } \\
\text { Entrants, } \\
\text { substituted } \\
\text { Products } \\
\end{array}$ \\
\hline & organization & $\begin{array}{c}\text { Strategy, } \\
\text { Structure, } \\
\text { Infrastructures, } \\
\text { Culture, } \\
\text { Management, } \\
\text { Human Resource }\end{array}$ \\
\hline & Individual & $\begin{array}{c}\text { Citizens, ICT } \\
\text { Experts }\end{array}$ \\
\hline $\begin{array}{l}\text { Primary } \\
\text { technological } \\
\text { inputs }\end{array}$ & ICT products & $\begin{array}{c}\text { Software, } \\
\text { Hardware, } \\
\text { Communication } \\
\text { Device }\end{array}$ \\
\hline $\begin{array}{c}\text { Primary } \\
\text { Management } \\
\text { Processes }\end{array}$ & $\begin{array}{l}\text { Management } \\
\text { Processes }\end{array}$ & $\begin{array}{c}\text { Planning, } \\
\text { Organizing, } \\
\text { Leadership, } \\
\text { Control, } \\
\text { Resource } \\
\text { allocating }\end{array}$ \\
\hline
\end{tabular}

\begin{tabular}{|c|c|c|}
\hline $\begin{array}{l}\text { Primary } \\
\text { e-service } \\
\text { Outputs }\end{array}$ & ICT Services & $\begin{array}{c}\text { E-commerce, E- } \\
\text { Government, E- } \\
\text { Education, E- } \\
\text { Health }\end{array}$ \\
\hline \multirow{3}{*}{$\begin{array}{c}\text { Primary } \\
\text { access }\end{array}$} & House hold & $\begin{array}{c}\text { Perceived ease } \\
\text { of use, Perceived } \\
\text { Usefulness, } \\
\text { Penetration } \\
\end{array}$ \\
\hline & Business & $\begin{array}{c}\text { Perceived ease } \\
\text { of use, Perceived } \\
\text { Usefulness, } \\
\text { Penetration }\end{array}$ \\
\hline & Government & $\begin{array}{c}\text { Perceived ease } \\
\text { of use, Perceived } \\
\text { Usefulness, } \\
\text { Penetration }\end{array}$ \\
\hline $\begin{array}{l}\text { primary } \\
\text { outcomes }\end{array}$ & Outcomes & $\begin{array}{c}\text { Individuals, } \\
\text { Business, } \\
\text { Government }\end{array}$ \\
\hline value & impacts & $\begin{array}{c}\text { Culture, Society, } \\
\text { Economy, } \\
\text { Policy, } \\
\text { technology }\end{array}$ \\
\hline
\end{tabular}

It is necessary to mention that considering only four primary e-Services (e-Commerce, eGovernment, e-Education and e-Health) is based on national priorities in development plans of the Iran

\section{Prioritizing building blocks of the $i$ - society value chain model}

Analytical Hierarchical process is one of comprehensive systems for multi-criteria decision making. In AHP, both quantitative and qualitative aspects of the decision making are investigated. In this paper we use AHP to prioritize for finding the weight of each proposed dimensions and factors. In this way there are 14 identified building blocks and 54 identified factors in total.

To pair-wise comparison it is prepared a questionnaire which help to assess Relative importance of the building blocks and dimensions of i-society value chain. In final phase, we used Expert choice software to analyze experts' opinions which its results illustrated in this following discussion. By using AHP and with calculation and inconsistency rate cancellation (which according to the diagram is 0.01 and acceptable due to less than 0.1 ) final prioritization of all building blocks have been proposed.

In the following, priority of each building block is determined for i-society in Iran subsequently. As Shown in Figure3, the diagram clearly shows that government, business and individual access, outcome and impact, managing process, e-services, national, individual, industry and organization enablers have most priority and environmental factors have least. 


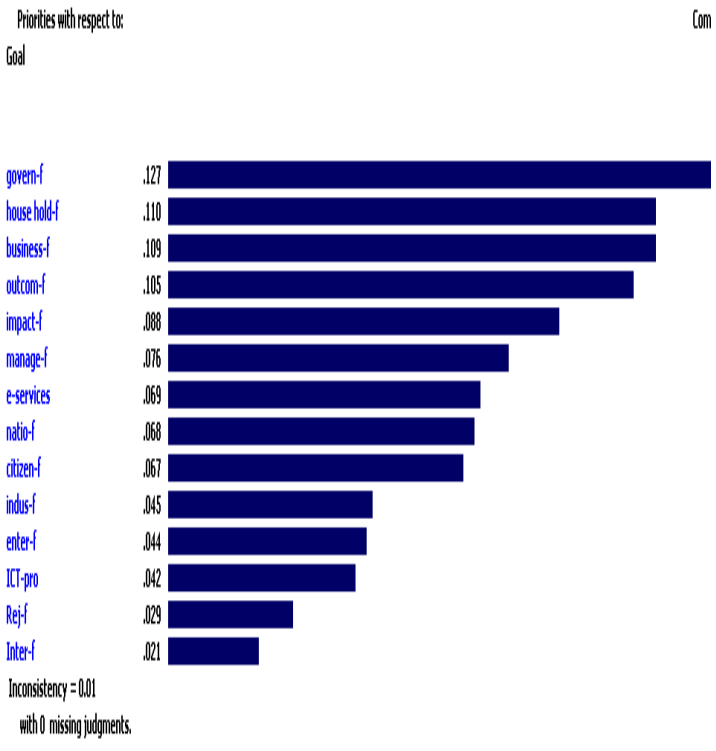

Figure 3. i-Society building blocks prioritization

In the following, priority of the factors for each dimension is determined subsequently:

According to Figure 4 economical dimension has the most priority among other international environmental dimensions, which follows by technical, political and social factors.

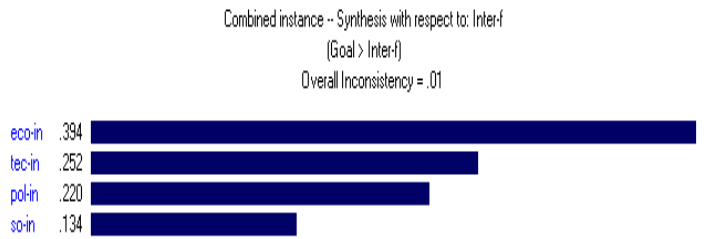

\section{Figure 4. International dimensions prioritization}

According to Figure 5 political/regulatory dimension has the most priority among other regional environmental dimensions, which follows by economical, technical and social components.

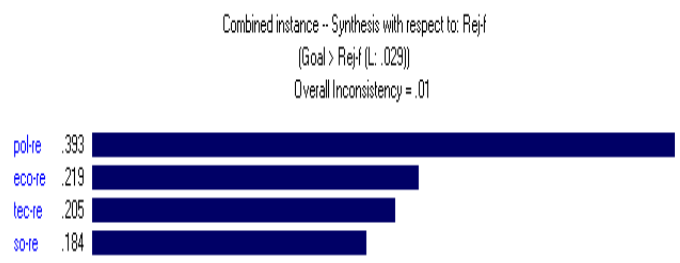

Figure 5. Regional dimensions prioritization

According to the Figure 6 social/cultural dimension is in the top of interior national list and economical, technical, political and $\mathrm{R} \& \mathrm{D}$ dimensions come after that.

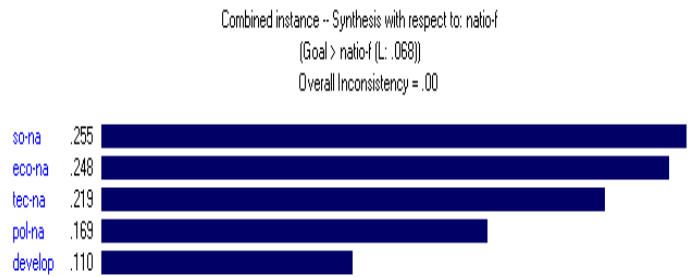

Figure 6. National dimensions prioritization

As illustrated in Figure 7 from industrial point of view, customers, new entrants, products, suppliers and competitors are identified as most important dimensions.

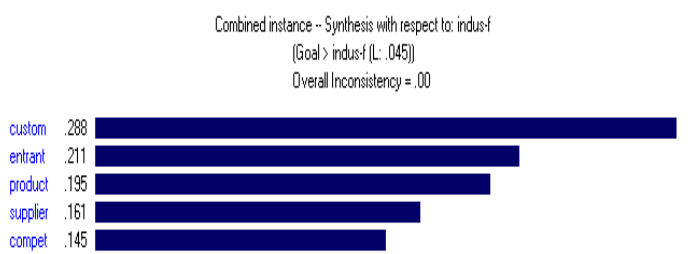

Figure 7. Industrial dimensions prioritization

Figure 8 clearly shows that most important dimensions in organizational aspect are management, human resources, and strategy, culture, structure and technical issues in order.

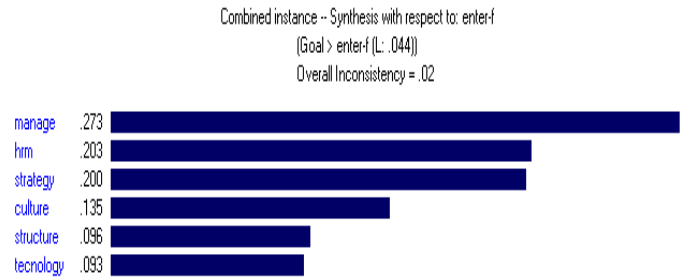

Figure 8. Organizational dimensions prioritization

According to Figure 9, citizens have been identified more important than ICT experts.

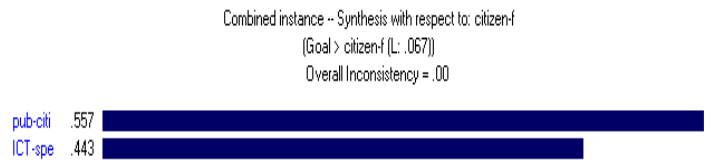

\section{Figure 9. Individual dimensions prioritization}

According to Figure 10 in managing process, planning and leadership have most important position, organization, control and resource allocation come after them. 


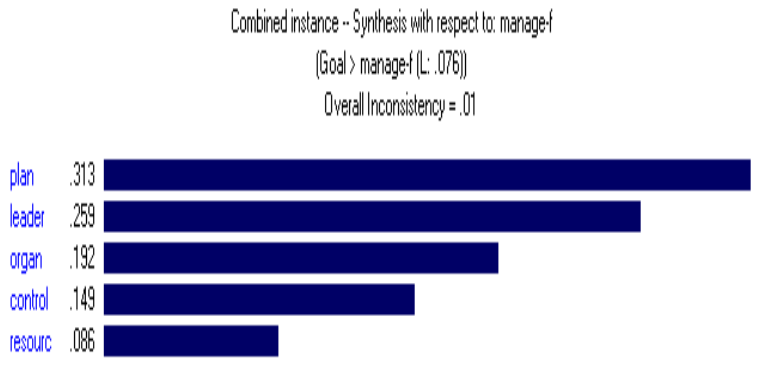

Figure 10. Managing process dimensions prioritization

According to Figure 11 e-commerce and egovernance services have been recognized as the most important services and after them e-learning and e-health take places.

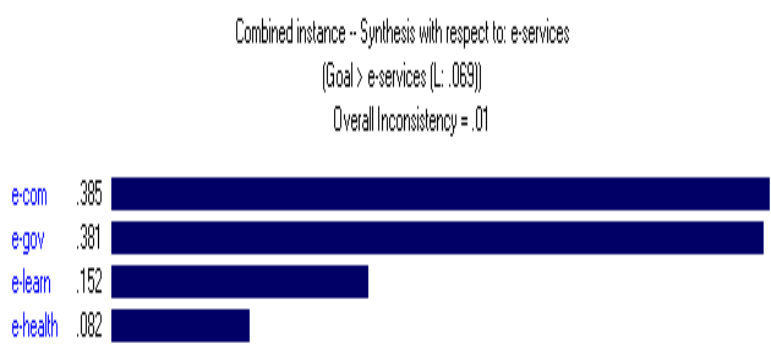

Figure 11. E-Service dimensions prioritization

In Iran's Domestic market, computer software has the top of the list which follow by telecommunication and ICT equipment and computer hardware.

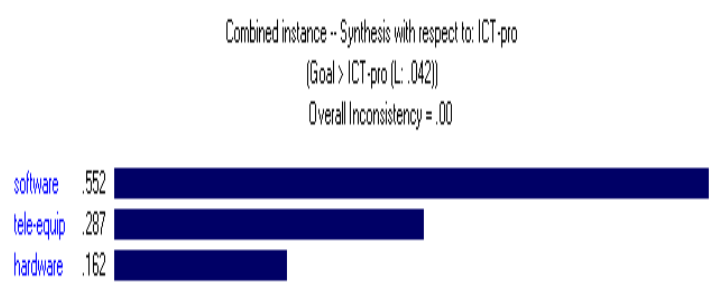

Figure 12. Technological product dimensions prioritization

According to Figure 13 in individual access, penetration rate is the most important dimension and perception of usefulness and ease of use stay behind that.

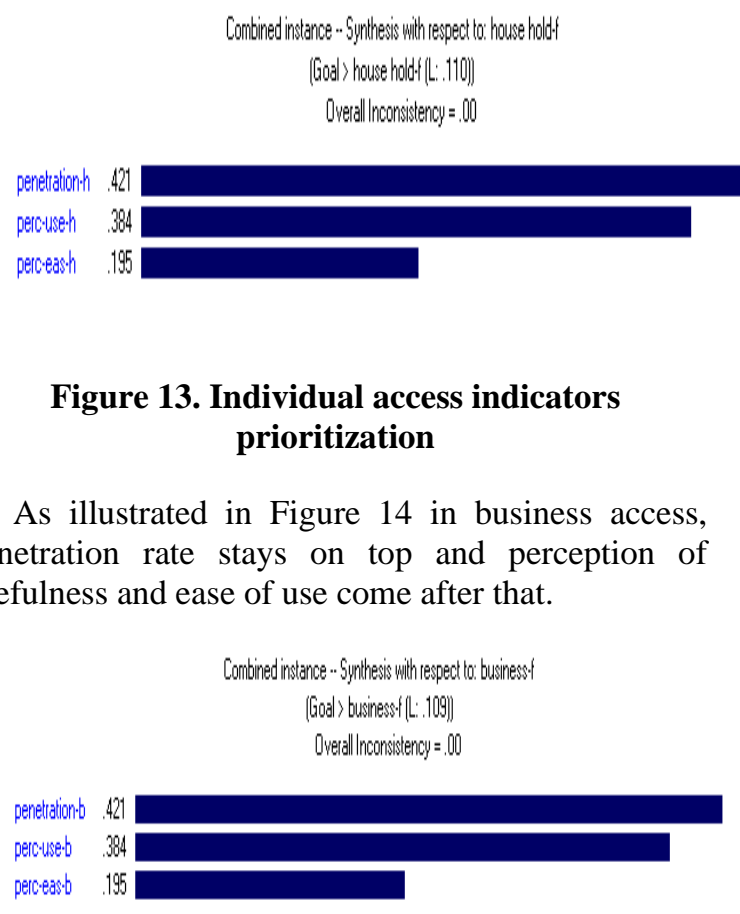

Figure 14. Business access indicators prioritization

In government access indicators, same as business access indicators, penetration rate stays on top and perception of usefulness and ease of use come after that.

Combined instance - Synthesis with respect to: govern.t

(Goal $>$ govem. $\{([:$ : 127))

Overal Inconsistency = .00

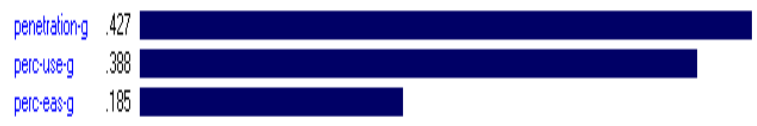

Figure 15.government access indicators prioritization

According to Figure 16 outcomes for businesses is the most important dimension and after that outcomes for government and citizens.

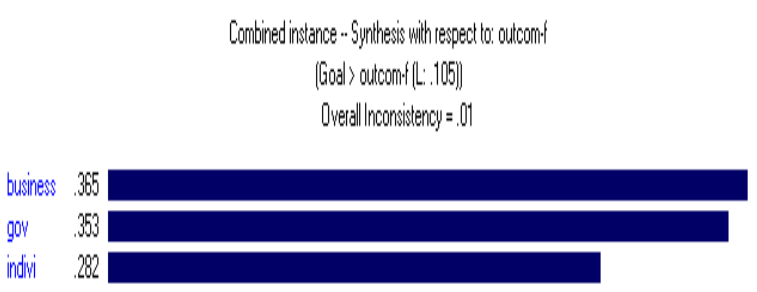

Figure 16. Outcomes dimensions prioritization 
According to Figure 17 periodically economical, social, cultural and political impacts are the most important dimensions.

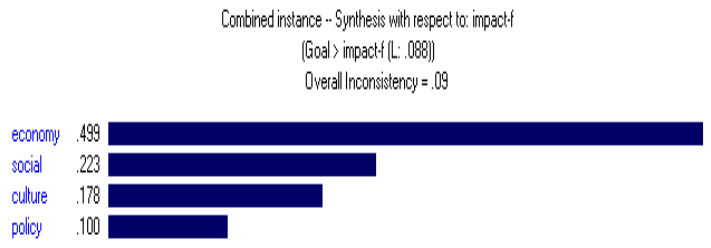

Figure 17. Impacts dimensions prioritization

Furthermore same as above calculations, it have been calculated for developed countries that those results have been explained in the last section.

\section{Case study: Information society assessment in IRAN}

Indicators are based upon the idea that statistical data provides evidence for the evaluation of current policies and future policy-making. Statistics underpin policies, and therefore, reliable statistical data and indicators regarding develop, manage, deliver, use, outcome and impact of ICT, help policy makers to formulate strategies related to ICT-driven economic growth and social development [1]

As mentioned in previous sections, the proposed model consists of building blocks and dimensions that enable periodic and comparative evaluation of country's progress toward an information society. To put this proposed model into the real operation, first, we define three main indicators for each dimension and then provide a questionnaire. After that, we can find strength and weakness of ICT in each building block and its related dimensions by Polling the idea and comments of Chief Executive Officers (CEO) and policy makers from both public and private companies. Amount of each dimension is estimated by averaging the given points of the related indicators, and then amount of each dimension has been multiplied by its weight (that as mentioned in last section, it is calculated by Analytical Hierarchical process). The score of each dimension can be compared with average score to determine the weakness of the country in that dimension. As illustrated in following Figure, score of each building block can be calculated by averaging related dimensions and final score of each country is equal to sum of the scores of the building blocks.

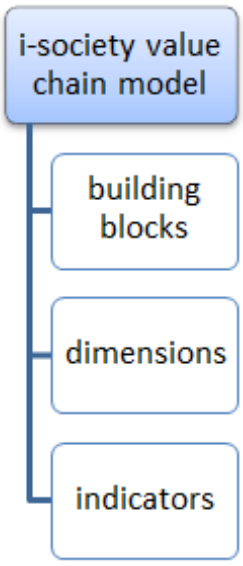

Figure 18. Interrelations between indicators, dimensions and building blocks of the proposed model

If the final score of the county reaches to more than average score for that element, it can be concluded that the country has good progress in developing information society. Based on our evaluation, i-society final score in IRAN shows 2.48 out of 5 . This means that almost $50 \%$ of objectives have been accomplished. The radar chart, depicted in Figure 19, shows the status of each i-society building block. To improve status of building blocks with low score, some possible solutions have been suggested.

According to Figure19, access of households and public organizations to ICT services, take the strong positions, but the other building blocks have scores less than average. Based on i-society value chain assessment model of IRAN, the following solutions can be suggested:

1- For improvement in supportive building block at, international level, the amount of import and export at this level should be increased. Additionally, absorbing more foreign investment can improve this building block.

2- For improvement in supportive building block,at regional level, the first thing is to increase the export of consulting services and ICT products and then having. Closer relationships with the similar countries in point of similarity in race, culture and language is strongly recommended.

3- For improvement in supportive building block at industrial level, there should be more facility for the suppliers in product, service, information and money exchange, and also need to raise trust among consumers for using the ICT products and services.

4- For improvement in supportive building block at organization level, they should try to align their business strategies with ICT plans. Another thing, which can improve the organization situation, is providing proper hardware, software and communicational infrastructure. 
5- For improvement in supportive building block at individual level, improving ICT literacy among public is a prerequisite. Additionally, there should be a balance between supply and demand of ICT experts.

6- For improvement in supportive building block at national level, there should be encouraging package for potential investors in ICT area. Increasing the e-content with national language (Farsi) and culture is another empowering factor for this block.

7- For improvement in primary technological building block, there is a need for developing a national broadband network and building required open source software.

8- For improvement in primary management process building block, the role and responsibility of each ICT players in the country should be clarified. The periodical monitoring on plans and projects is another suggestion.

9- For improvement in primary ICT service building block, there is a need to develop a national portal and to have integration in interorganizational systems.

10- For improvement in primary access building block, there should be a common understanding among enterprises about ICT ease of use and ICT usefulness.

11- For improvement in primary outcome building block, it is recommended that the ICT utilizing should be according to justice and anticorruption activities.

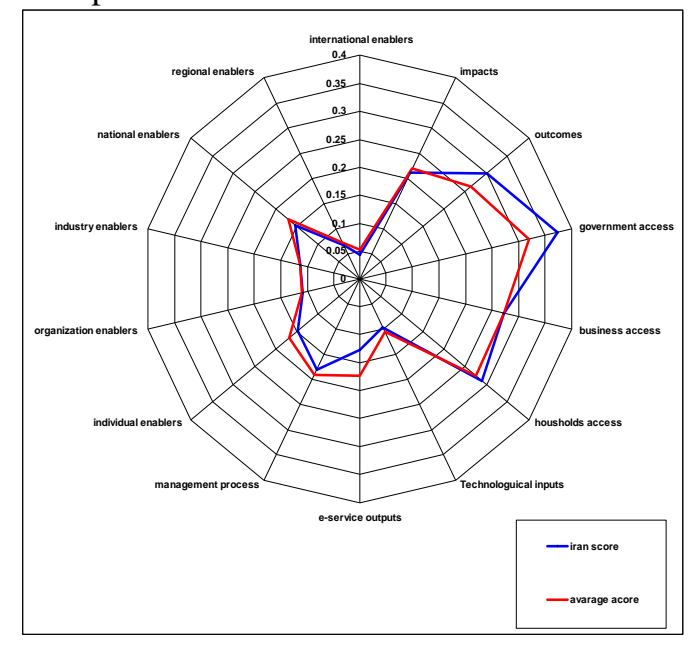

Figure 19. Radar chart for showing current status of each building block

\section{Conclusions}

In this research and we provided an analyze of existing assessment models with special focus on isociety and i-society readiness models. Based on a value chain approach, we defined supportive and primary building blocks to propose an "i-society value chain model" and then determined all related dimensions and indicators.

After that, we weighted and prioritized dimensions and factors of i-society readiness by using AHP approach. One of the results of this research was considering different priorities for isociety dimensions in different countries, because different countries have different specifications and so they seek different values. We can come to this conclusion that local experts in Iran consider primary "managerial" building block of ICT, as the most important factor in i-society development, but global experts put emphasize on other primary building blocks.

One of the possible causes of these different viewpoints is this fact that in Iran country, despite of vast resources and infrastructure availability, just because of bad management and absence of proper mechanisms, we haven't been successful in reaching to the ICT goals. So this building block is considered bold, but in developed countries providing prerequisites pave the way to the ICT achievement.

Another important finding from this comparison is that none of local and global experts paid attention to supportive building blocks such as international and regional ones. So attention to the environmental building blocks should be considered as an important factor in developing i-societies.

\section{References}

[1] United Nations, 2005, The Context And Role Of Indicators In The Information Society, Information Society Indicators, Economic And Social Commission for Western ASIA

[2] Menou, M.J. and Taylor, R.D., 2006, "A Grand Challenge": Measuring Information Societies", The Information Society, 22: 261-267, Copyright Taylor \& Francis Group, LLC, ISSN: 0197-2243 print / 1087-6537 online, DOI: 10.1080/01972240600903904.

[3] Bridge, "E-Ready for What? E-Readiness in Developing Countries: Current Status and Prospects toward the Millennium Development Goals", bridge.org, 11 May 2005

[4] Choucri,N.,Maugis,V.,Madnick,S.,Siegel,M., ."Global ereadiness for what?" Cambridge: MIT, 2003.

[5] Castells, M. (1996), the Rise of the Network Society. The Information Age: Economy, Society and Culture, Vol. I, Blackwell Publishers, Oxford.

[6] Tikkanen H., Parvinen Petri M.T., 2006, "Planned and spontaneous orders in the emerging network society”, Journal of Business \& Industrial Marketing, 38-49, Emerald Group Publishing Limited [ISSN 0885-8624],[DOI 10.1108/08858620610643166]. 
[7] Magoulas,G. D.,Lepouras, G., Vassilakis, C., 2007, "Virtual reality in the e-Society", Springer-Verlag London Limited

[8] Bridge.org. ()."Comparison of e-readiness assessment models, 2001

[9] Dada, D.,"E-Readiness for Developing Countries: Moving the Focus from the Environment to the Users", London School of Economics and Political Science, The Electronic Journal on Information Systems in Developing Countries, 2006

[10]D.Sachs, J., "Readiness for the Networked World, a Guide for Developing Countries", Center for International Development at Harvard University, 2003

[11] Budhiraja, R., S. Sachdeva, "E-Readiness Assessment (India)"Department of Information Technology, 11, 2002

[12] Davidrajuh, R., "Fuzzy Approach for Measuring EReadiness", International Conference on Computational Intelligence for Modeling, IEEE, 2006.

[13] Al-Osaimi, K., Alheraish, A., Haj Bakry, S., An Integrated STOPE framework for e-readiness assessments, 18th National Computer Conference, 2006.

[14] Hourali, M., Fathian, M., Montazeri, A., A Model for Ereadiness Assessment of Iranian Small and Medium Enterprises, Journal of Faculty of Engineering, Vol.41, No.7.Feb.2008, pp.969-985.

[15] Mohamadian, M.,Ghasemzadeh,F., E-policy Making: A System Approach Based on Evaluating ICT's Impacts, IEEE, 2005.

[16] APEC. "E-Commerce Readiness Assessment guide, 2000.

[17] WITSA. (2000).International survey of e-commerce.

[18] Computer Systems Policy Projects, CSPP. A Self Assessment tool for Communities: CSPP Readiness Guide, 2004.

[19] Hanafizadeh, others, 2005," a collection of ICT development assessment models and domestic ICT development indexes measurement". Iran Telecom Research Center.

[20] elahi \& others,"design an e-Readiness assessment model for e-Commerce deployment in companies", economical study center, Ministry of commerce, 2005.

[21]Economist Intelligence Unit, the economist intelligence unit/pyramid research Rankings, 2007.

[22] McConnell International, Risk E-Business: Seizing the Opportunity of Global Readiness, 2001.

[23] Ziaei Pour, E. and Khoshalhan, F., Bazazan, F., Taghizadeh, A., Mohammadian, A., "Proposed model for national e-readiness based on system approach", 6th International Conference on Information Technology: New Generations, ITNG 2009, Las Vegas, Nevada, USA.
[24] Alican, F., 2007, "Experts without expertise: E-society projects in developing countries - The case of Turkey", Information Polity, 255-263, IOS Press and the authors.

[25]Porter, M. E. (1996). What is strategy? Harvard Business Review, November-December, 61-78.The value chain. 